\title{
Quebraderos litúrgicos en el diseño de arquitectura religiosa actual
}

\author{
Liturgical concerns in the design of current religious architecture
}

Giuseppe Giacalone · Investigador independiente (Barcelona, España), giacalone@t113arquitectura.com

Maria del Mar Viladot·Investigadora independiente (Barcelona, España), viladot@t113arquitectura.com

Eloi Aran Sala·Investigador independiente (Barcelona, España), e.aran@t113arquitectura.com

Recibido: $30 / 07 / 2019$

Aceptado: $17 / 01 / 2020$

(ec) By-NC https://doi.org/10.17979/aarc.2020.7.0.6322

\section{RESUMEN}

A lo largo de los últimos diez años, el Taller de Arquitectura T-113 de Barcelona ha desarrollado diferentes intervenciones en espacios celebrativos, aplicando la innovación litúrgica propuesta por el Concilio Vaticano II en diálogo con el espacio, los usuarios y el programa proyectual. Dicha práctica profesional ha conllevado una tensión y aprendizaje constantes que se pretenden comunicar a través de la presentación de diversos proyectos realizados, agrupados en tres apartados. El primer apartado trata sobre intervenciones que compaginan el uso litúrgico con otras actividades pastorales; el segundo, trata sobre el cuidado en el diseño de los arhketopos - lugares fundacionales- de órdenes religiosas; el tercero, versa sobre la implementación de instalaciones de confort ambiental y visual en reformas de espacios sacros vinculadas con la actividad litúrgica.

\section{PALABRAS CLAVE}

Taller de Arquitectura T-113, Barcelona, arquitectura religiosa, liturgia.

\section{ABSTRACT}

Over the last ten years, the T-113 Architecture Workshop in Barcelona has developed different interventions in celebratory spaces applying the liturgical innovation proposed by the Vatican Council II in dialogue with the space, the users and the project program. This professional practice has led to constant tension and learning that are intended to be communicated through the presentation of various projects carried out grouped into three sections. The first section deals with interventions that combine liturgical use with other pastoral activities; the second deals with the care in the design of the arhketopos, or foundational places of religious orders; the third is about the implementation of environmental and visual comfort facilities in reforms of sacred spaces linked to liturgical activity.

\section{KEYWORDS}

Taller de Arquitectura T-113, Barcelona, religious architecture, liturgy.

Cómo CITAR: Giacalone, Giuseppe, Maria del Mar Viladot y Eloi Aran Sala. 2020. «Quebraderos litúrgicos en el diseño de arquitectura religiosa actual». Actas de Arquitectura Religiosa Contemporánea 7: 170-181. https://doi.org/10.17979/aarc.2020.7.0.6322. 

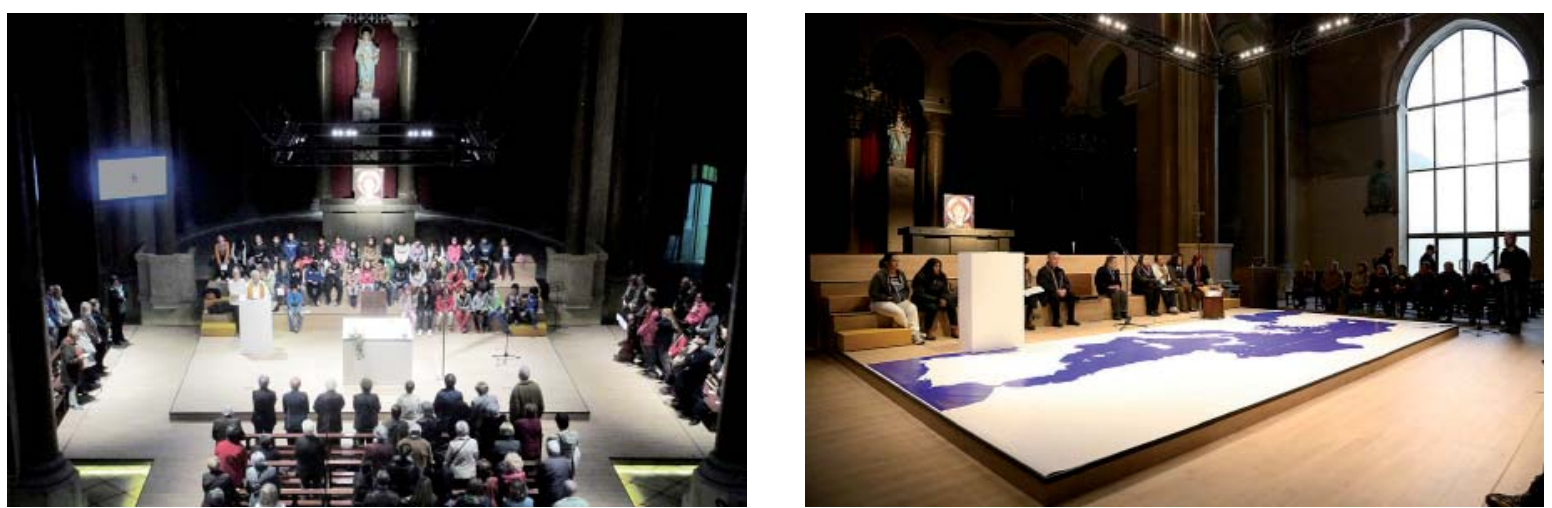

Fig. 01. T113-Taller de Arquitectura. Templo de Santa Madrona, Poble-Sec-Barcelona, 2014; celebración eucarística. Fig. 02. Oración comunitaria sobre la inmigración en la misma iglesia.

\section{INTRODUCCIÓN}

Un quebradero sugiere un tema conflictivo o complejo, pero también puede sugerir un lugar donde se quiebra un tiempo o un espacio profano para dar lugar al tiempo y espacio sacros mediante la acción litúrgica de la comunidad, intentando dar respuesta a la problemática del sentido de la vida. Por otro lado, algunas acciones proyectuales que pudieran parecer hacer añicos ciertos esquemas de celebración o disposiciones de elementos tradicionales actualizan y refuerzan el sentido celebrativo del espacio. Sobre todo ello se pretende reflexionar partiendo de la experiencia del despacho T113-Taller de Arquitectura durante estos últimos años.

\section{COMPAGINACIÓN DE ACTIVIDADES LITÚRGICAS Y OTROS USOS PASTORALES}

El elevado número de bienes inmuebles de carácter sacro, ligado a una decreciente práctica confesional y el diálogo de la fe en una sociedad altamente secularizada, ha puesto sobre la mesa diversas propuestas de compaginación del espacio sacro con otros usos no litúrgicos. ${ }^{1}$ Este apartado deja de lado los casos de desacralización y se centra más en los espacios que intentan seguir las directrices más próximas para la compaginación de usos no cultuales con espacios de carácter sacro. ${ }^{2}$
El primer caso que se trae a colación es la reforma del templo parroquial de Santa Madrona del PobleSec, en Barcelona, realizada en 2014. ${ }^{3}$ El objetivo de la operación consistió, primeramente, en incorporar una disposición más asamblearia dentro de un edificio de planta basilical; luego, el comitente también apostaba por una regulación del espacio y una economía de las instalaciones dependiendo del número de asistentes previsible en los diferentes tipos de celebración o acto pastoral. Estas peticiones se concretaron en el diseño de un suelo técnico de madera que se extendía por la nave principal y el transepto a modo de T; colocando el nuevo mobiliario litúrgico en el centro, bajo la cúpula y convenientemente iluminado por un baldaquín; y diseñando un guarda-muebles móvil con posibilidad de quedar fijado y de disponer de toma eléctrica en cada uno de los cruceros de la nave principal. Con esta nueva disposición, la comunidad parroquial ganó en proximidad y calidad espacial de las celebraciones o actos pastorales, al mismo tiempo que ganaba también un nuevo nártex o atrio de gentiles interno al templo donde poder relacionarse entre sí o también como espacio cultural propio, abierto al barrio (Fig. 01-02). ${ }^{4}$

El segundo caso - en evidente relación con el anterior- es la reforma de la iglesia del Colegio Lestonnac de Barcelona, de 2018.5 También se trata de una operación de implementación de un espacio 

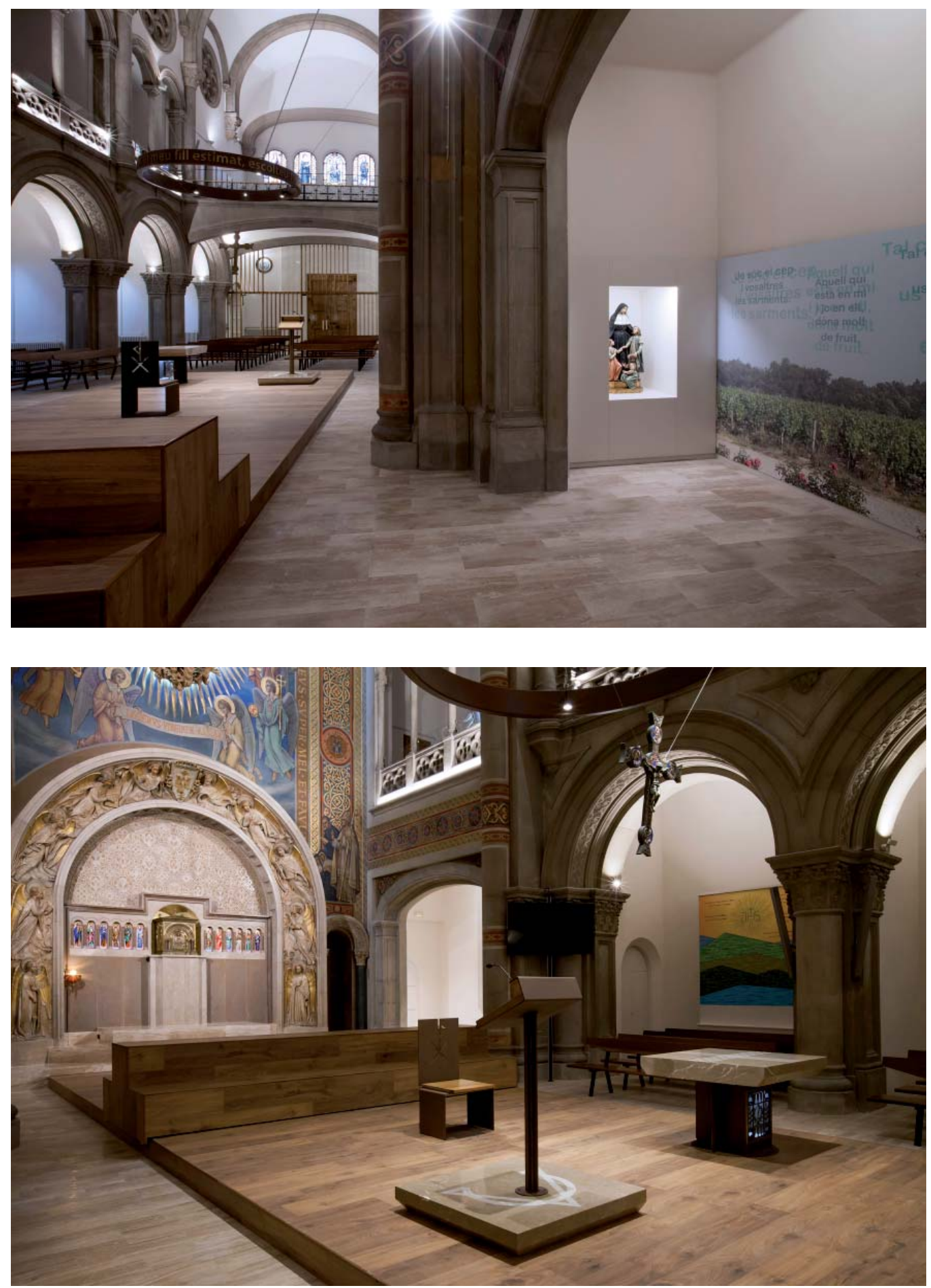
celebrativo central en un contenedor de planta basilical, y de regulación de espacios según la asistencia prevista, para ofrecer mayores prestaciones a la pastoral escolar. Los objetivos se concretaron en un nuevo presbiterio a modo de lengua de madera que corría desde el tabernáculo hasta el nuevo presbiterio - con la nueva disposición del mobiliario litúrgico-, situado en una posición más central, de modo que se ocupaba parte de las capillas laterales y se creaba una grada móvil debajo del arco triunfal de la iglesia. Esta operación posibilitaba la creación de un ámbito posterior al presbiterio, a modo de capilla del Santísimo para la devoción individual o de pequeños grupos, que se incorporaba al espacio celebrativo restante para grandes ocasiones. Otros aspectos que se tuvieron en cuenta fueron la creación de los retablos móviles laterales para poder actuar a modo de separadores espaciales ${ }^{6} \mathrm{o}$ la substitución del antiguo cancel en un nuevo nártex vidriado que posibilitaba la apertura y visualización del espacio desde la calle; así como la sectorización y uso externo del espacio del coro, una antigua gradería reconvertida en espacio plurifuncional en relación directa con la nave central (Fig. 03-04).

En relación a los quebraderos litúrgicos, cabe apuntar el aprendizaje realizado por el Taller en ambas operaciones. En la primera, la relación con el altar consagrado y el antiguo presbiterio presentaba un problema de desertización, y se encontró una solución interpretando el antiguo presbiterio como lugar significado de la presencia de lo santo, incorporando un icono de Cristo encima del altar y poniendo más énfasis en la imagen de la santa titular del templo, situada en una peana al fondo del ábside.

En el segundo caso, el mobiliario litúrgico incorpora la piedra del antiguo altar como base del ambón y de la mesa del altar - simétrico respecto el Cristo suspendido del nuevo baldaquín circular-, ofre-

Fig. 03. T113-Taller de Arquitectura. Reforma de la iglesia del colegio Lestonnac, Barcelona, 2018; vista del acceso interior.

Fig. 04. Vista del presbiterio. ciendo una catequesis espacial sobre las dos partes de la celebración eucarística. El baldaquín circular representa según la tradición el cielo abierto, la comunicación de Dios que es su Hijo, el cual permanece en la Palabra y el sacramento de la eucaristía. Estos elementos se reafirman en su carácter sacro por el uso del mismo diseño y material, así como por la simbología incorporada: la fusión del alfa y el omega grabadas en la base del ambón, la cruz de cuatro brazos grabada en el altar, y el crismón perforado en el respaldo de la sede. En ambos casos también se presentó un problema de seguimiento de las imágenes audiovisuales por parte de los asistentes; esta dificultad se solucionó con la disposición de dos pantallas televisivas en los dos extremos de una de las diagonales del presbiterio.

Con respecto a la disposición del mobiliario litúrgico de la reforma de la iglesia de Lestonnac — puesto a modo de triángulo equilátero bajo la proyección del baldaquín circular, poniendo en dos vértices alineados el ambón y el altar y dejando la sede para el vértice posterior-, cabe apuntar la justificación de diversas críticas:

1. El altar debe estar en medio y no desplazado. Aunque el altar debe tener una posición central, no es cierto que tenga que ocupar el centro geométrico del espacio, tal como argumenta Juan Miguel Ferrer Grenesche: «La centralidad significativa y funcional le caracteriza (al altar), sin que pretenda que coincidir con la centralidad geométrica».

2. La sede no debería estar en el medio, sino a un lado. Esto es clericalismo. «La sede para el celebrante y los ministros se colocará de tal forma que, según la estructura de cada iglesia, sea bien visible a los fieles, y el celebrante aparezca realmente como el presidente de toda la comunidad de los fieles» (Inter Oecumenici, 92). «La sede del sacerdote celebrante debe significar su ministerio de presidente de la asamblea y de moderador de la oración. Por lo tanto, su lugar más adecuado es vuelto hacia el pueblo, al fondo del presbiterio» (Ordenación General del Misal Romano, 310);

3. El ambón toma demasiado protagonismo y no está bien pisar el alfa y el omega grabados en la antigua losa de altar. «Hay que poner especial atención 


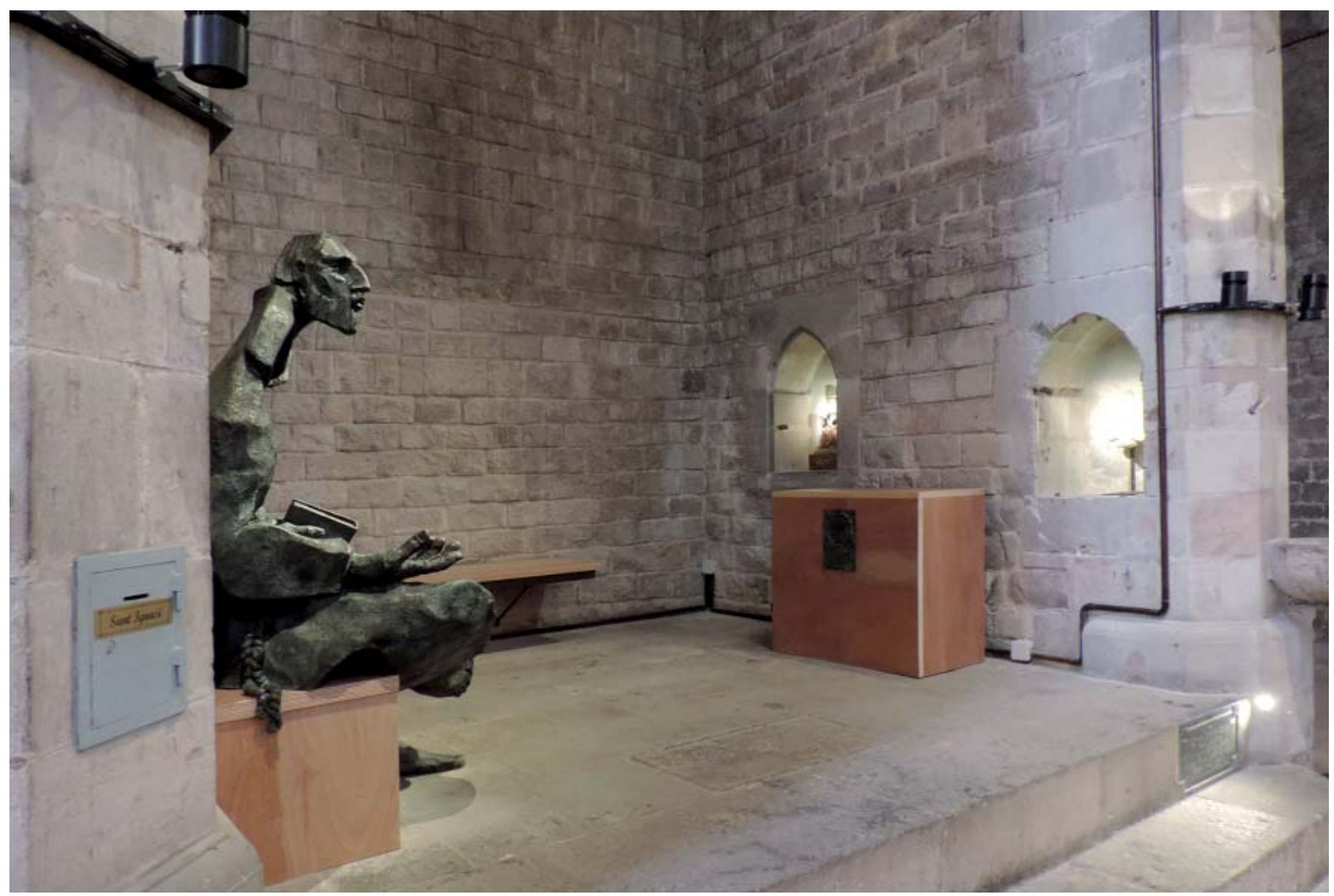

Fig. 05. T113-Taller de Arquitectura. Capilla de san Ignacio de Loyola en la basílica de Santa María del Mar, Barcelona, 2016.

en el ambón como lugar litúrgico desde el que se proclama la Palabra de Dios. Se debe colocar en un lugar bien visible, y al que se dirija espontáneamente la atención de los fieles durante la liturgia de la Palabra. Conviene que sea fijo, como elemento escultórico en armonía estética con el altar, de modo que represente visualmente el sentido teológico de la doble mesa de la Palabra y de la Eucaristía. Desde el ambón se proclaman las lecturas, el salmo responsorial y el pregón pascual; pueden hacerse también desde él la homilía y las intenciones de la oración universal» (Verbum Domini, 68); «De este modo, la sacramentalidad de la Palabra se puede entender en analogía con la presencia real de Cristo bajo las especies del pan y del vino consagrados. Al acercarnos al altar y participar en el banquete eucarístico, realmente comulgamos el cuerpo y la sangre de Cristo. la proclamación de la Palabra de Dios en la celebración comporta reconocer que es Cristo mismo está presente y se dirige a nosotros para ser recibido» (Dei Verbum, 56).

Referente al hecho de subir al ambón y ponerse encima de la antigua losa del altar, puede resultar que alguien tenga la sensación de hacer un acto de apostasía, sobre todo después de que saliera a la luz la película Silencio de Martin Scorsese (2016), donde los primeros cristianos japoneses son forzados a la apostasía pisando una imagen del Cristo. Otros pueden argumentar que poner la losa de base en el suelo recuerda a lo de los enemigos puestos a «el estrado de sus pies» (Salmo 110,1). A esta crítica se puede 
responder que el mundo entero es el estrado de los pies de Dios (Is 66,1) y que también se identifica la expresión con el mismo templo o lugar de oración (Salmo 132,7). ¿Cuándo en una iglesia antigua, pisamos una losa funeraria para ir a comulgar, tenemos la sensación de que estamos negando a la persona que descansa allí, o, más bien no nos recuerda que la fe recibida proviene y es deudora de una tradición que ha sido posible por el legado de los antepasados?

\section{CUIDADO Y DISEÑO DE LUGARES FUNDACIONALES}

A lo largo de la historia de la Iglesia, los diferentes carismas del estamento de la vida religiosa han producido modificaciones en los edificios sacros y en su disposición interior. Lejos de quedar obsoletos, los espacios propios de estas instituciones religiosas incorporan nuevos retos y refuerzan el sentido celebrativo a partir de los documentos del Concilio Vaticano II, especialmente de Perfectae Caritatis (1965), donde se apuntaba que

la adecuada adaptación y renovación de la vida religiosa comprende a la vez el continuo retorno a las fuentes de toda vida cristiana y a la inspiración originaria de los Institutos. (...) Redunda en bien mismo de la Iglesia el que todos los Institutos tengan su carácter y fin propios. Por tanto, han de conocerse y conservarse con fidelidad el espíritu y los propósitos de los Fundadores, lo mismo que las sanas tradiciones, pues, todo ello constituye el patrimonio de cada uno de los Institutos (n. 2).

Esta invitación a redescubrir las propias fuentes de cada instituto religioso se asemeja al retorno a los arkhetopos - los lugares originales - de las relaciones de una pareja. Hay que volver al lugar del primer encuentro, del enamoramiento, aunque éste se haya transformado ya en un amor institucionalizado, formando una familia religiosa. Esta llamada a volver a los orígenes de la relación - especialmente de la relación con el Dios que libera y da vida - no es extraña en la tradición bíblica. Por ello nos encontramos con la imagen del desierto como lugar de encuentro, lugar donde acallar los rumores y ponerse a la escucha, como hicieron ya los Padres del desierto o los mismos profetas:
Ve y habla a la ciudad de Jerusalén; grita para que lo oiga bien: ‘¡Así dice el Señor! Recuerdo que cuando eras joven, me eras fiel; que cuando te hice mi esposa, me amabas y me seguiste a través del desierto, tierra donde nada se cultiva' (Jer 2,2).

El primer caso de este apartado es la reforma de la capilla de can Ignacio de Loyola en la basílica de Santa María del Mar de Barcelona, de 2016. La capilla en cuestión está elevada un par de peldaños con respecto a la cota de la nave principal y se encuentra en el lateral izquierdo. En uno de los peldaños existe una placa de piedra con una inscripción que recuerda que san Ignacio de Loyola pedía caridad, como estudiante pobre ahí sentado. Ese hecho sucedía durante la segunda estancia del santo en la Ciudad Condal (1524-26), y es el único lugar que queda de la Barcelona ignaciana, puesto que la casa donde vivió se derribó por la creación de la calle Princesa, y el lugar de estudio se derrumbó por la creación de la plaza del Ángel, en Vía Layetana, dos operaciones de esponjamiento de la densa trama urbana de la Barcelona medieval.?

La intención del proyecto era pasar de una intervención de carácter meramente informativo a uno mistagógico, a saber, que ayudase al encuentro con el Transcendente. A tal efecto se procedió a crear una escultura de san Ignacio - obra del artista Lau Feliu - a modo de peregrino, descalzo y sentado en el extremo de un nuevo banco corrido mirando hacia el altar. El hecho de bajar la imagen del santo - que anteriormente estaba dispuesta in altum -, era una invitación para que los usuarios - a veces peregrinos del Camino Ignaciano que va desde Loyola hasta Barcelona-, se sentaran al lado del santo y, cómo el, dirigiesen su mirada hacia el altar principal de la basílica de Santa María del Mar. Reforzando el relato $\mathrm{y}$ ofreciendo también otros elementos devocionales propios de la espiritualidad ignaciana, se dispusieron una imagen de la Vírgen de Aránzazu y de la Creu del Tort en dos pequeñas hornacinas existentes en uno de los muros opuestos al banco corrido. Dado que la capilla es el punto final del Camino Ignaciano y es lugar de celebraciones para peregrinos, se incorporó también un pequeño altar móvil, significado con el símbolo de la Compañía de Jesús (Fig. 05). 

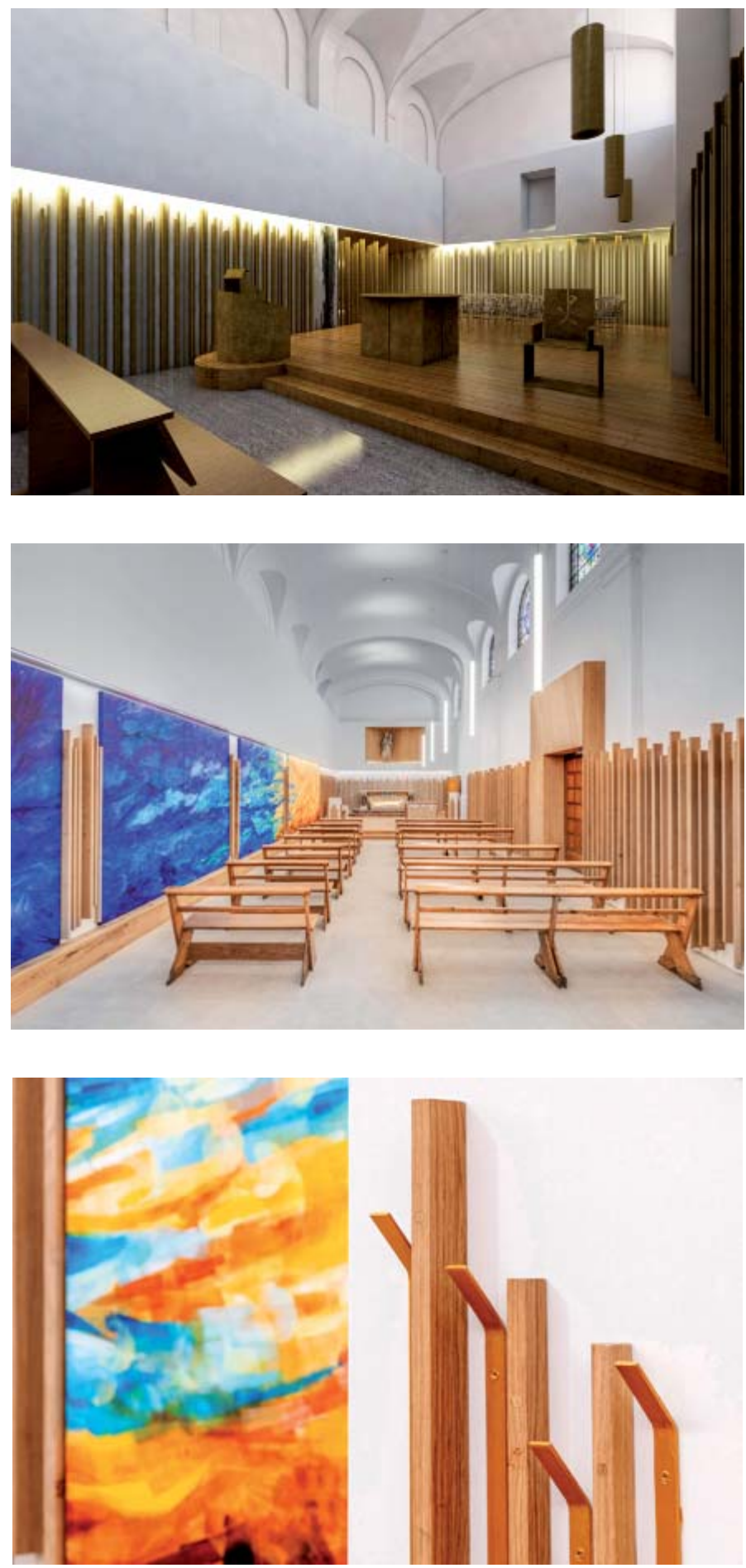

Fig. 06. T113-Taller de Arquitectura. Reforma de la iglesia de la Compañía de María, Burdeos (Francia), 2019; imagen del anteproyecto.

Fig. 07. Primera fase.

Fig. 08. Detalle del mobiliario litúrgico que hace referencia al texto bíblico de Éxodo 3 . 
El segundo caso es la reforma de la iglesia de la Compañía de María, conocida popularmente por el apellido de su fundadora, santa Juana de Lestonnac, en su ciudad natal, Burdeos (Francia), de 2019. La primera fase de la reforma limitó su ámbito de actuación a la actualización de instalaciones y al tratamiento de la piel perimetral de la nave de la iglesia. La composición de la reforma del espacio interior responde al tradicional diálogo vertical de tierra-cielo que encontramos en la mayoría de los templos y obras de carácter sacro. Por ello se dispuso un primer nivel en la base de los paramentos que responde a la evocación del bosque de La Mothe; dicha referencia se consigue con el trabajo de perfiles de madera de diferentes tamaños dispuestos según un patrón de repetición variable. Esta nueva piel de madera transcurre de forma casi ininterrumpida a lo largo de la iglesia e incorpora accesos secundarios y espacios técnicos. También en este primer nivel terrenal aparece incorporado en la composición de perfiles de madera en la parte izquierda, un mural pictórico de la hermana dominica Brigitte Loire, que representa el paso de la oscuridad a la luz en la Noche del Císter de santa Juana.

Con respecto a la planta y el suelo, se ha procedido a un doble uso de material: pétreo en la nave y de madera en la zona de presbiterio, el cual se ha ampliado para avanzar la sede, el ambón y el altar según la propuesta para la segunda fase del proyecto, cuando se pueda disponer del espacio del actual archivo para la nueva ubicación del panteón de santa Juana de Lestonnac, a modo de capilla lateral.

El mobiliario litúrgico se ha diseñado en referencia al texto bíblico de la teofanía de Moisés (Ex 3), a saber, tomando la imagen de la zarza ardiente donde Aquél que es se comunica para liberar a su pueblo del mismo modo que Cristo se comunica hoy a través de la Palabra y la eucaristía. Por ello, encontramos otra vez las escuadrías de madera intercaladas con pletinas metálicas que sugieren el fuego.

En un segundo nivel, destacando por su claridad en referencia a lo celeste, se dispone un tabique corrido superior descolgado respecto el muro original en dos de las cuatro caras del recinto. Esta intervención permite leer el espacio como senda espiritual o reco- rrido; al mismo tiempo, facilita la iluminación de la pintura inferior y sirve de pantalla para reflejar la luz natural proveniente de los ventanales superiores del lado opuesto. Presidiendo el muro testero en dicho tabique perimetral, se dispone la imagen de la Virgen con el Niño y un racimo de uvas, conocida como $L a$ Virgen de la cuna, tan estimada por la Compañía de María por ser la imagen que presidía la fachada del primer templo de la orden religiosa antes de la Revolución Francesa. La imagen tiene de fondo el mismo acabado de madera que encontramos en el suelo del presbiterio, lo cual hace referencia a esa realidad terrenal que, con María, es asumida en el ámbito de lo celeste. Este fondo - que ahueca el tabique para poder disponer la imagen-, se abre de forma asimétrica hacia los ventanales superiores, para que la imagen tenga luz y como metáfora de cómo María es aquella persona que es tomada como referencia de escucha de la Palabra. No podía ser de otra manera, si se quiere responder al lema propio de la institución religiosa, Llenad vuestro nombre, Compañía de María. Rompiendo la horizontalidad de esta doble lectura tierra-cielo del espacio, aparecen tan sólo en el lado derecho las luminarias verticales que, a modo de antorcha, nos remiten por su ritmo a la apreciada fiesta de la Presentación de la Virgen en el Templo, caracterizada por una procesión de candelas. En la segunda fase se procederá a la creación de una capilla lateral para el traslado de los restos de santa Juana, creando un espacio con doble uso (Fig. 06-08).

En relación a los quebraderos litúrgicos, ambos proyectos nos alertan de la importancia y la riqueza que pueden aportar los santos en el quehacer cotidiano de muchas instituciones, y en la configuración de un relato de soporte respecto los espacios celebrativos, sin dejar de significarse como tales a través del triple foco del mobiliario litúrgico de sede, altar y ambón; es decir, sin menoscabar un diseño donde Cristo sea percibido como aquél que convoca a la asamblea cristiana. Valga ello también de reflexión para una arquitectura religiosa moderna que, muchas de las veces, ha sido tildada de apofática o protestante por una depuración a veces excesiva de las mediaciones propias de la tradición católica. 

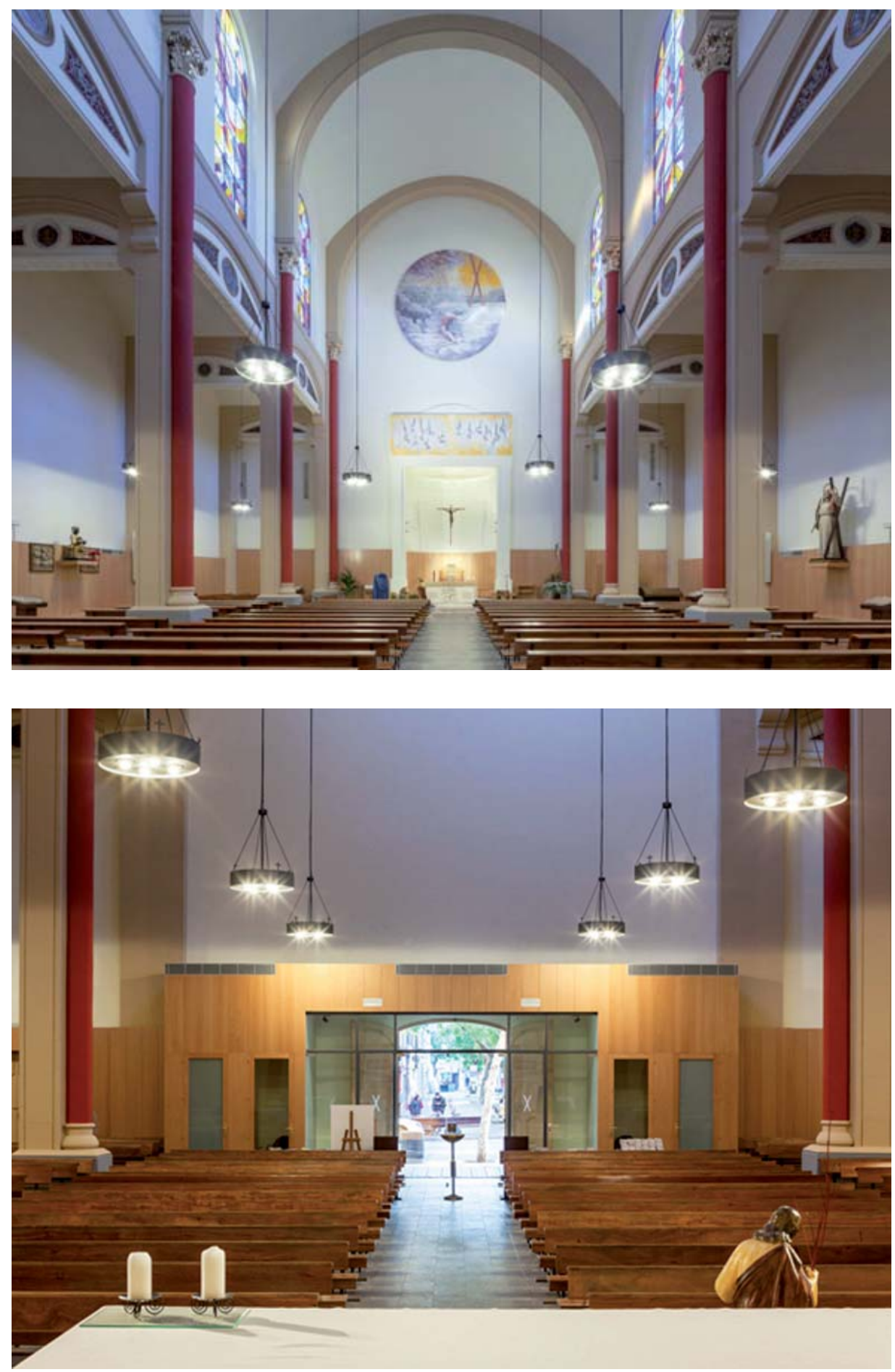


\section{IMPLEMENTACIÓN TECNOLÓGICA EN ESPACIOS SACROS EN RELACIÓN A LA ACTIVIDAD LITÚRGICA}

Hacia los años cincuenta del siglo XX se edificó el Centro Borja, el teologado de la Compañía de Jesús en Sant Cugat del Vallés (Barcelona). En la iglesia de este equipamiento, los radiadores de agua caliente estaban camuflados en los altares laterales, los cuales tenían unas rendijas por las cuales circulaba el aire. No sabemos si la intención era ofrecer servicios litúrgicos recién horneados, pero valga la anécdota para tratar la compleja relación entre la tecnología y el espacio sacro. Cabe preguntarse, por ejemplo, si es indigno mostrar la maquinaria constructiva y tecnológica propia de una época en la que - de forma análoga a como Le Corbusier decía que la casa era una máquina de habitar-, los arquitectos modernos han buscado crear máquinas de rezar.

El primer caso es la reforma del templo parroquial de Santa Eulalia de Vilapicina, en Barcelona, de 2018. Contrariamente a los dos primeros casos presentados, aquí se buscaba ampliar la capacidad de la iglesia original - obra del arquitecto Josep Domènech Estepà, de la cual no se llegó a construir el transepto ni el ábside - y su adecuación litúrgica, así como sus instalaciones climáticas y lumínicas. La iglesia ya había sido reformada anteriormente para ponerla al día de las indicaciones conciliares, con el sello característico del trío conformado por el aparejador Toni Cantó, el escultor Tomàs Bel y el pintor Llucià Navarro que se puede encontrar en muchas parroquias catalanas. A pesar del lavado de cara de dicha intervención, el altar seguía alejado de la comunidad celebrante, el presbiterio permanecía como un lugar apartado y el frontal como un muro poco significado. A tal efecto, se procedió a situar el sagrario en el eje de la nave y al fondo del ábside, en una peana con un banco corrido a ambos lados; se avanzó el altar y el ambón; se dio una nueva forma semicircular al presbiterio, en analogía a la curva del

Fig. 09. T113-Taller de Arquitectura. Reforma de la iglesia parroquial de Santa Eulalia de Vilapicina, Barcelona, 2018. Fig. 10. Cancel de acceso. ábside, para acercarlo a la comunidad, y se dispusieron bancos en los laterales del presbiterio. Para el gran muro frontal, se contó con la intervención del pintor muralista Josep Minguell, el cual propuso una imagen circular de grandes dimensiones con referencias a la titular del templo, que seguía la forma curva de las bóvedas de la nave. En este caso, la novedad - integrada y discreta - vino de la creación de un zócalo alto corrido de madera a lo largo de todo el templo, que incorporaba las peanas para las imágenes religiosas con otro banco para aumentar la capacidad de asistentes, así como el paso de las instalaciones para el confort climático. Este mismo zócalo servía para la creación de un nuevo cancel que ampliaba y mejoraba la accesibilidad, al mismo tiempo que incorporaba los confesionarios, simétricamente dispuestos sobre el acceso principal (Fig. 09-10).

El segundo caso es la reforma del templo de la Mare de Déu del Roser - de titularidad de la orden dominicana- en Barcelona, de 2018. Aquí se trataba de separar el espacio de culto respecto a la sala polivalente situada detrás del ábside, que conectaba con el claustro neogótico de la comunidad dominica, así como la actualización de los acabados interiores del templo - aún ennegrecidos por la Guerra Civil española-, las imágenes y las instalaciones. Para ello, se procedió a la instalación de un suelo radiante con la maquinaria al exterior, con un nuevo pavimento marcando el eje direccional del acceso al presbiterio; toda la iglesia se pintó de nuevo, poniendo en contraste los elementos estructurales respecto a la claridad de los paramentos verticales; se dispuso un espacio de acogida y dos confesionarios en los laterales del acceso principal; se creó un zócalo integrado en la parte baja de los muros para el paso de instalaciones; y se encargó a Goretti Pomé la figuración del nuevo fondo del presbiterio, separado ahora del espacio multiusos posterior con la obra titulada Epíclesis (Aran 2018) (Fig. 11).

\section{ALGUNAS CONCLUSIONES}

Habida cuenta que la liturgia es fons et culmen de la vida de la comunidad cristiana, no cabe duda que también lo es de forma análoga referente al programa y expresión del edificio que acoge su actividad. 


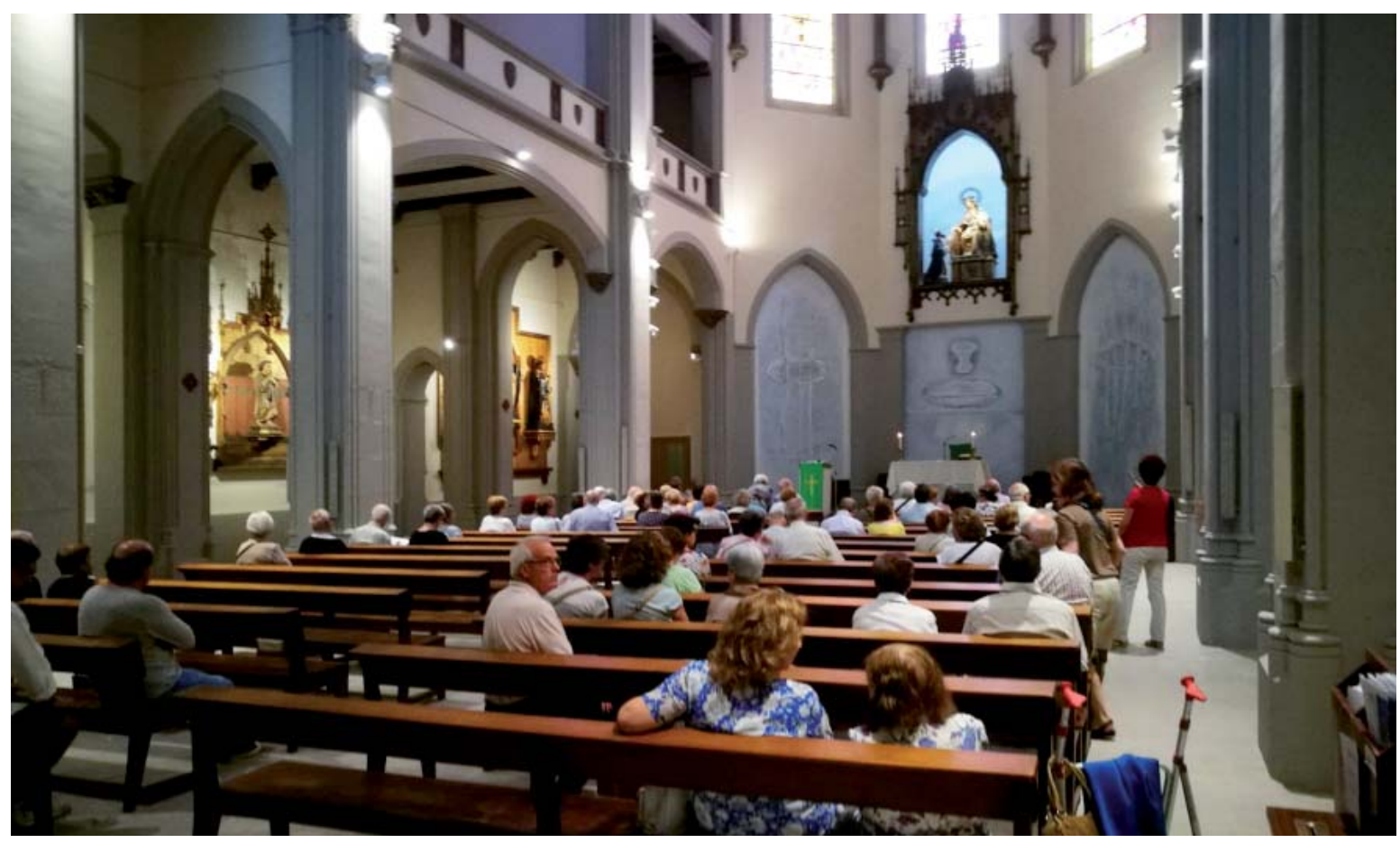

Fig. 11. T113-Taller de Arquitectura. Reforma de la iglesia de la Mare de Déu del Roser (padres Dominicos), Barcelona, 2018.

Ahora bien, la experiencia proyectual nos ha llevado a caer en la cuenta de que ésta no puede ser tomada tan solo como un conjunto normativo, sino que es también una invitación al juego creativo que le es inherente y que, al mismo tiempo, dialoga constantemente con las características de los hombres y comunidades contemporáneas; ya sea éste un diálogo con las fuentes bíblicas, los carismas eclesiales, los ritos, la tecnología o la imaginación de la actividad pastoral que desea comunicar una Buena Nueva para hoy.

Este juego compositivo, que acerca la tarea del arquitecto al de la Sabiduría creadora (Prov 8,2730 ), supone una gran responsabilidad, pero al mismo tiempo, la alegría y los gozos propios de la acción evangelizadora. Sí, ciertamente la acción proyectual de un espacio sacro conlleva un buen quebradero de cabeza, pero en los requiebros de la tarea se vislumbra también una presencia inagotable.

\section{BIBLIOGRAFÍA}

Aran Sala, Eloi. 2018. Epíclesi. Reforma de l'església dels dominics a Barcelona. En Betel. Arquitectura, art i religió (blog). Consultado el 28/07/2019, http://bit.ly/38ZNLw4.

Asociación Española de Profesores de Liturgia, ed. 2012. Arquitectura y liturgia. Actas de las XXXVI jornadas de la AEPL. San Lorenzo del Escorial (Madrid), 30/08-01/09/2011. Barcelona: Centre de Pastoral Litúrgica.

Azcárate Ristori, Isabel de. 1993. El monasterio de La Enseñanza de Barcelona, 16451876. Barcelona: Promociones y Publicaciones Universitarias.

Benedicto XVI. 2010. Exhortación apostólica postsinodal Verbum Domini sobre la Palabra de Dios en la vida y en la misión de la Iglesia 
(30 de septiembre). Consultado el 31/07/2019, http://bit.ly/36QovXk.

Bouyer, Louis. 2000. Arquitectura y liturgia. Bilbao: Grafite.

Camino Ignaciano. 2019. Camino Ignaciano. Consultado el 28/07/2019, https://caminoignaciano.org.

Ferrer-Gresneche, Juan Miguel. 2012. Orientaciones teológico-litúrgicas del Magisterio Eclesial actual sobre espacios litúrgicos. En Asociación Española de Profesores de Liturgia, 32.

Pablo VI. 1965. Constitución Dogmática Dei Verbum sobre la Divina Revelación (18 de noviembre). Consultado el 31/07/2019, http://bit.ly/2Q6woRC.

Pablo VI. 1965. Decreto Perfectae Caritatis sobre la adecuada renovación de la vida religiosa (28 de octubre). Consultado el 31/07/2019, http://bit.ly/36Z2zcs.

Sagrada Congregación de Ritos y el Consilium. 1964. Instrucción Inter Oecumenici. Consultado el 31/07/2017, http://bit.ly/34c1htO.

Sagrada Congregación para el Culto Divino y la Disciplina de los Sacramentos. 2002. Ordenación General del Misal Romano. Consultado el 21/11/2019, http://bit.ly/34epHmA.

\section{NOTAS}

1. Tenemos ejemplos de ello en la iglesia parroquial St. Marien, en la pequeña ciudad de Müncheberg (Alemania), una antigua iglesia del Císter que aloja un compartimiento interior que funciona como biblioteca municipal y centro cultural; o la iglesia de Sankt Peter, en Colonia, también en Alemania, que desde hace más de veinte años se ha especializado en el diálogo entre la fe y el arte sin renunciar tampoco a su uso litúrgico.

2. Muestra de la conflictiva relación del uso litúrgico con otros usos no pastorales es el documento Criteris per a l'ús de les esglésies i les capelles per a actes extralitúrgics (Criterios para el uso de las iglesias y capillas para actos extralitúrgicos) de mons. Xavier Novell, obispo de la diócesis de Solsona (2017); aunque también encontramos otros precedentes como la Instrucción sobre los conciertos en las iglesias, publicada por la Sagrada Congregación para el Culto Divino en 1987.

3. El templo parroquial de Santa Madrona del Poble-Sec fue proyectado por Adrià Casademunt en estilo neogótico a finales del siglo XIX.

4. El proyecto sigue pendiente de otras fases, que incluyan la nueva ubicación de la pila bautismal en el eje central de la nave, así como la adecuación de la antigua capilla bautismal, hoy en desuso, en capilla abierta con acceso directo desde la calle Tapioles.

5. La iglesia del colegio Lestonnac-Barcelona fue originariamente diseñada por Joan Martorell i Montells en el conjunto del nuevo convento de la Enseñanza para la Compañía de María en el ensanche de Barcelona, puesto que el antiguo se derribó para la abertura de la calle Ferran el año 1873-75. A pesar de conservar su estructura original, todo su interior fue reconstruido después de la guerra civil española por el arquitecto Francesc Mestre Salas en los años cuarenta. De la iglesia original solamente quedan el frontón de acceso desde la calle Aragón y el mosaico descubierto durante las obras de reforma, que ha sido convenientemente restaurado y dispuesto en el lateral derecho del sagrario.

6. Los retablos laterales de la iglesia del colegio Lestonnac-Barcelona incorporan, a su vez, dos relatos que hacen referencia al paisaje de Palestina y los lemas propios de esta orden religiosa, en su parte derecha; y un skyline de Barcelona vinculado a las festividades y hechos históricos de la orden de la Compañía de María y Barcelona, en su parte izquierda. Estos motivos han sido elaborados con un mosaico de lápices de colores enganchados al retablo con vinilos. En su parte posterior se ha dispuesto una pizarra para rotuladores para dar versatilidad catequética y docente al espacio.

7. El paso de San Ignacio de Loyola por Barcelona, mientras emprendía sus estudios con el maestro Ardèvol, así como sus vivencias en la basílica de Santa María del Mar, quedan recogidos en su Autobiografía, n. 54-55.

\section{PROCEDENCIA DE LAS ILUSTRACIONES}

Fig. 01-11. Archivo T113-Taller de Arquitectura. 